\title{
Recycled Al Reinforced with Oxide Nanoparticles Produced by Stir-Casting Method
}

\author{
A. Santos-Beltrán ${ }^{1}$, V. Gallegos-Orozco ${ }^{1}$, M. Santos-Beltrán ${ }^{2}$, F.J. Baldenebro-Lopez ${ }^{1}$, C.D. \\ Gómez-Esparza ${ }^{2}$, I. Ronquillo-Ornelas ${ }^{1}$ and R. Martínez-Sánchez ${ }^{2}$ \\ ${ }^{1}$ Universidad Tecnológica de Chihuahua Sur, Km. 3.5 Carr. Chihuahua a Aldama, C.P. \\ 31313. Chihuahua, Chih. México \\ ${ }^{2}$ Centro de Investigación en Materiales Avanzados (CIMAV), Miguel de Cervantes No. 120, \\ C.P.31109, Chihuahua, Chih., México
}

Aluminum alloys reinforced with hard nanoparticles named Metal Matrix Nanocomposites (MMNCs) are very attractive in many applications in the industry, this kind of materials exhibit improved mechanical properties with relatively low contents of reinforcement. Automotive and aerospace industries are demanding these composites for critical applications taking into account their low density and high temperature resistance characteristics. MMNC's are materials reinforced with hard particles (e.g. oxides and nitrides) with size ranging from $10 \mathrm{~nm}$ to $100 \mathrm{~nm}$. In the present work, nanocomposites based aluminum with hard nanoparticles of $\mathrm{TiO}_{2}$ and $\mathrm{CeO}_{2}$ were fabricated by combining two techniques such as mechanical milling and the stir-casting method. Compared to other routes, melt stirring process has some important advantages, e.g., the wide selection of materials, better matrixparticle bonding, easier control of matrix structure, simple and inexpensive processing, flexibility and applicability to large quantity production and excellent productivity for nearnet shaped components [1,2]. Nanoparticles and metallic powders, in the weight ratio of Recycled $\mathrm{Al} /$ nanoparticles $=3$, were separately milled using a Spex ball mill in uncontrolled atmosphere during $2 \mathrm{~h}$. The device and milling media used were made from hardened steel. The milling ball to powder weight ratio was set to 5:1. Consolidated samples were added into molten recycled $\mathrm{Al}$ using a resistance furnace equipped with a graphite stirring system. Each cylinder was hot extruded in a direct extrusion system at $550{ }^{\circ} \mathrm{C}$. The specimens in both asmilled and as-sintered conditions were studied by scan electron microscopy (SEM) and atomic force microscopy (AFM). The SEM bright-field image (see Fig. 1a) shows the microstructure of the $\mathrm{Al}-\mathrm{TiO}_{2}$ nanocomposite, the inset shows a close up image of the $\mathrm{TiO}_{2}$ nanoparticles dispersed into the recycled $\mathrm{Al}$ matrix; these particles are in the size range of about 80 to $100 \mathrm{~nm}$. Fig. 1b shows the AFM topography image of the $\mathrm{Al}-\mathrm{TiO}_{2}$ composite after the hot extrusion process, the image reveal a homogeneous crystallite size distribution of about 50 to $100 \mathrm{~nm}$. The inset shows the profile of the crystallite.

Fig. 2a shows the SEM bright-field image of the microstructure of the $\mathrm{Al}-\mathrm{CeO}_{2}$ nanocomposite after the hot extrusion process; the image also shows the presence of some fiber-shaped $\mathrm{CeAl}$ intermetallic compound. In the inset is clearly observed the $\mathrm{CeO}_{2}$ nanoparticles dispersed into the recycled $\mathrm{Al}$ matrix. The Figure $1 \mathrm{~b}$ shows the crystallite size distribution where most of these crystallites are below $100 \mathrm{~nm}$ in size.

The presence of these hard nanoparticles dispersed into the recycled Al prevents by the pinning effect, the excessive increase of the crystallite during thermo-mechanical extrusion process. The combined effect of hard nanoparticles dispersion and the small crystallite size, improved the mechanical properties of the recycled $\mathrm{Al}$ matrix.

References

[1] C. Suryanarayana, Nasser Al-Aqeeli. Progress in Materials Science 58 - Issue 4 (2013), 383-502.

[2] H. Abdoli, H. Asgharzadeh, E. Salahi. J. Alloys. Compd 473 (2009), 116-122. 


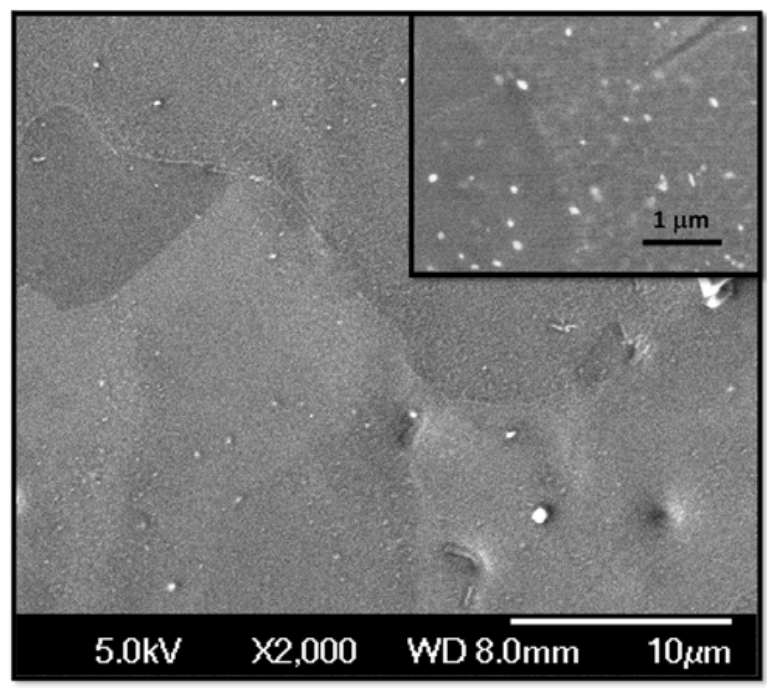

a)

Fig.1. a) SEM bright-field image that shows the $\mathrm{Al}-\mathrm{TiO}_{2}$ microstructure and the inset shows the $\mathrm{TiO}_{2}$ nanoparticles dispersion into the $\mathrm{Al}$ matrix. b) AFM image that shows the crystallite size of the $\mathrm{Al}-\mathrm{TiO}_{2}$ nanocomposite matrix and inset shows the height profile of the crystallite.

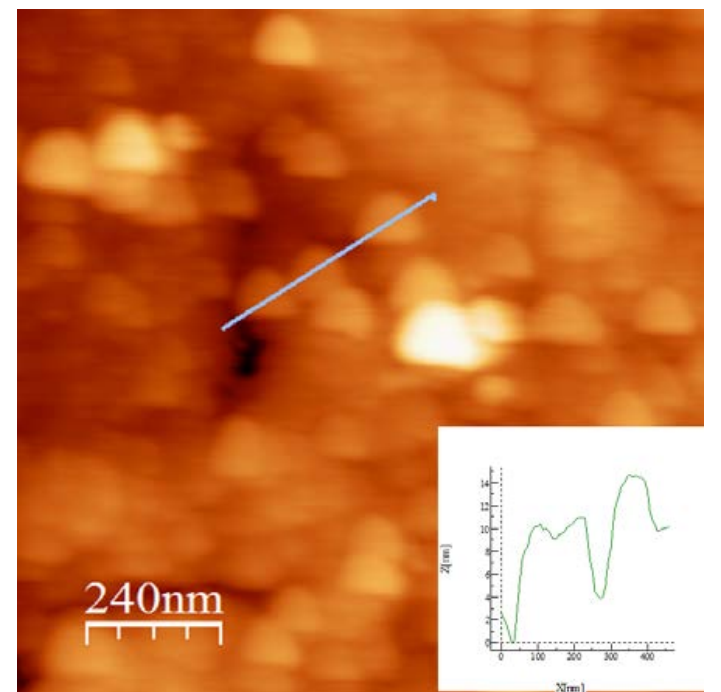

b)

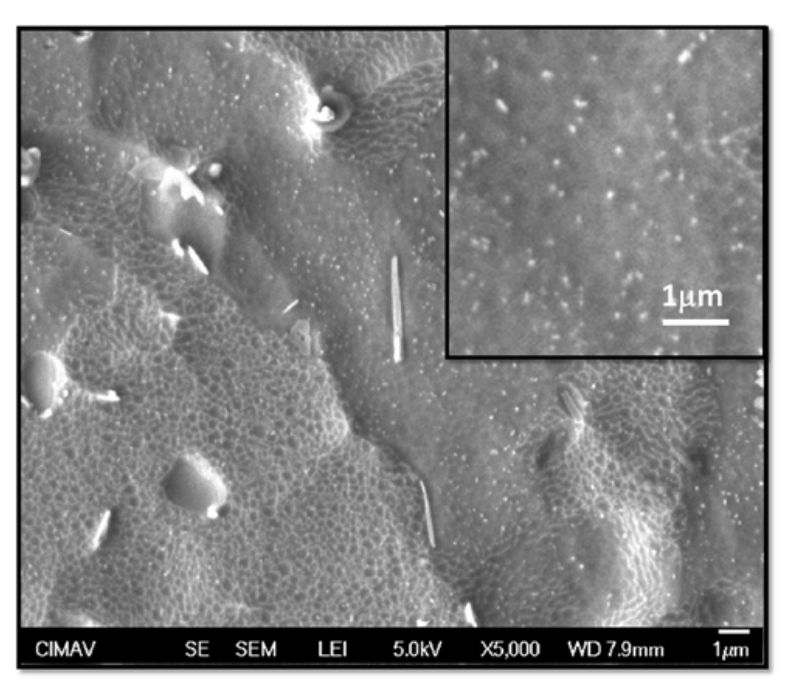

a)

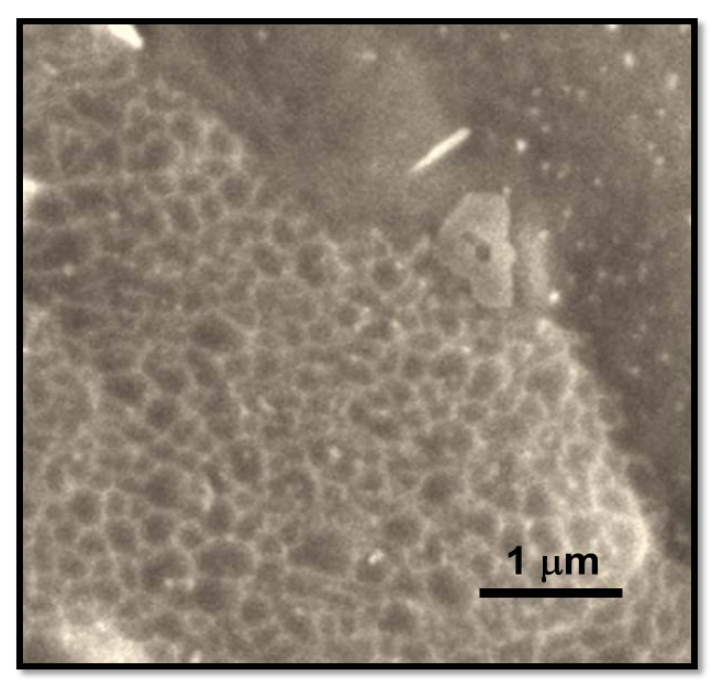

b)

Fig.2. a) Microstructure of the $\mathrm{Al}-\mathrm{CeO} 2$ sample (SEM bright-field image), the inset shows a homogeneous nanoparticle dispersion into the Al matrix, b) SEM bright-field image that shows the crystallite size distribution. 